\title{
POSITRON ANNIHILATION IN HELIUM CHARGED Ni SAMPLES
}

\begin{abstract}
J. PAJAKK
Institute of Physics, Pedagogical University, Oleska 48, 45-951 Opole, Poland

AND B. ROZENFELD

Institute of Experimental Physics, Wrocław University

pl. Maxa Borna 9, 50-204 Wroclaw, Poland

The angular correlation curves of annihilation quanta and isochronal annealing curves for the plastically deformed nickel samples charged with helium have been measured. The results indicate that helium is effectively trapped at crystal lattice defects and is released from them at the temperature below $350 \mathrm{~K}$.
\end{abstract}

PACS numbers: 78.70.Bj

\section{Introduction}

Among many experiments used for the investigation of the behaviour of helium atoms in metals the positron annihilation technique (PAT) is successfully employed as well. The formation of helium defect complexes as well as the formation of helium bubbles in steel [1], $\mathrm{Al}[2,3]$ and $\mathrm{Ni}$ [4] has been studied by PAT. In the present work PAT is used for studying the behaviour of helium atoms in the presence of crystal lattice defects produced by plastic deformation of $\mathrm{Ni}$ samples.

\section{Experimental}

Ni samples of purity not worse than $99.999 \%$ were defected by cold rolling. After $72 \%$ reduction the sample thickness was $0.22 \mathrm{~mm}$. The samples were cathodically charged with helium in a plasma produced by a low pressure electrical discharge. The voltage between cathode, that was the $\mathrm{Ni}$ sample, and anode was $700 \mathrm{~V}$ and the current $5 \mathrm{~mA}$.

Both angular correlation and isochronal annealing curves were measured with a standard spectrometer with a long slit geometry. 


\section{Results and discussion}

Angular correlation curves have been measured for well annealed Ni samples $\mathrm{Ni}(\Theta)_{\mathrm{a}}$, well annealed $\mathrm{Ni}$ samples charged with helium $\mathrm{Ni}(\Theta)_{\text {aHe }}$, cold rolled $\mathrm{Ni}$ samples $\mathrm{Ni}(\Theta)_{\mathrm{d}}$ and cold rolled $\mathrm{Ni}$ samples charged with helium $\mathrm{Ni}(\Theta)_{\mathrm{dHe}}$.

The results are represented as the relative difference curves in Figs. 1, 2 and 3. Figure 1 shows the relative difference for the cold rolled and well annealed samples. In Fig. 2 we represent the relative difference curve for the well annealed and the annealed sample containing helium and in Fig. 3 the relative difference for both cold rolled pure and helium containing samples is displayed. Figures 4 and 5 present isochronal annealing curves for cold rolled pure and helium charged $\mathrm{Ni}$ samples, respectively.

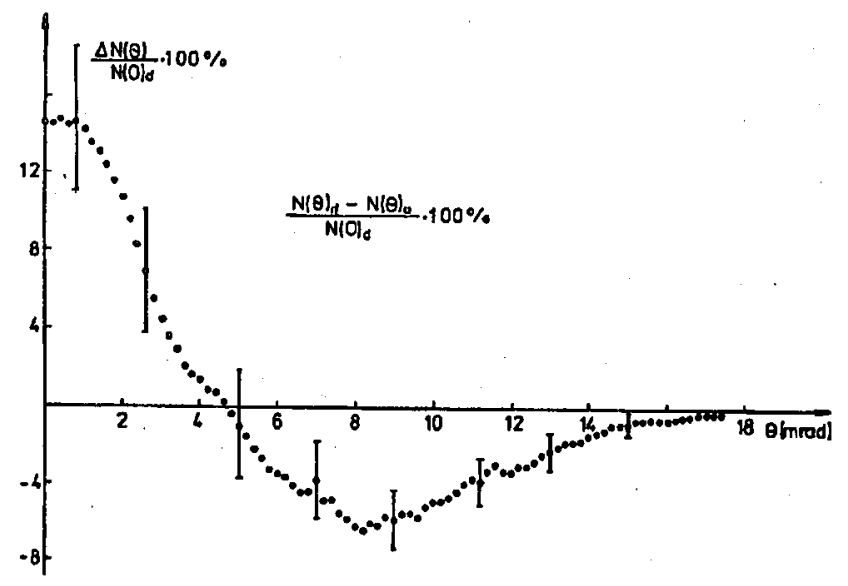

Fig. 1. Relative difference curve of the angular correlation curves for defected by cold rolled and well annealed $\mathrm{Ni}$ samples.

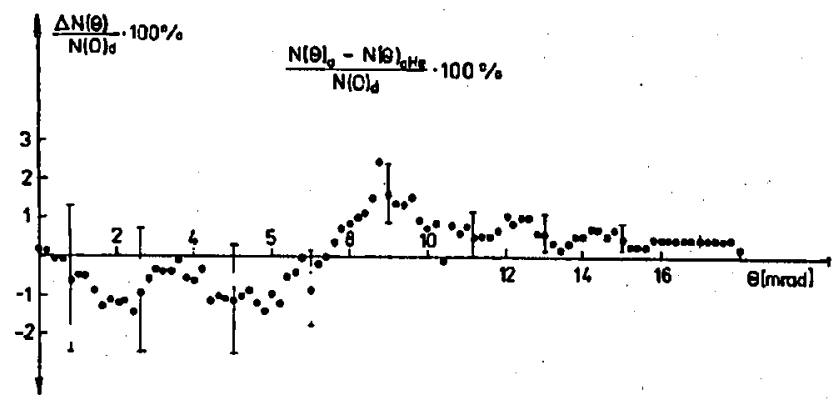

Fig. 2. Relative difference curve of the angular correlation curves for well annealed helium free and charged with helium $\mathrm{Ni}$ samples. 


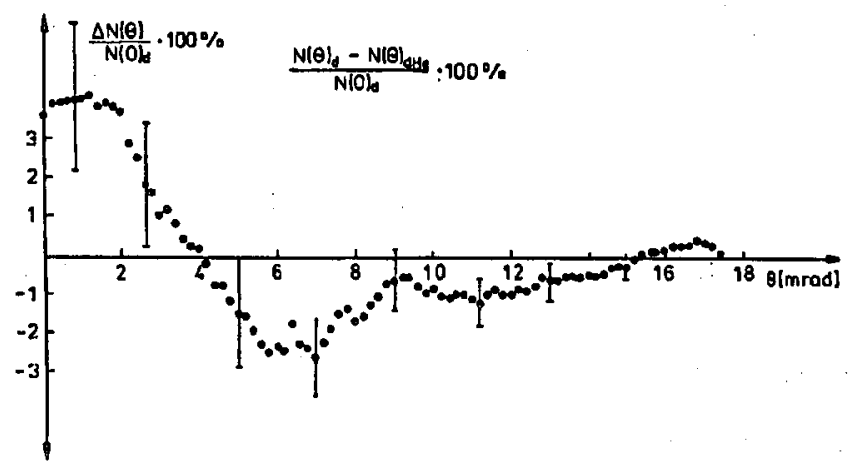

Fig. 3. Relative difference curve of the angular correlation curves for defected by cold rolled helium free and charged with helium Ni samples.

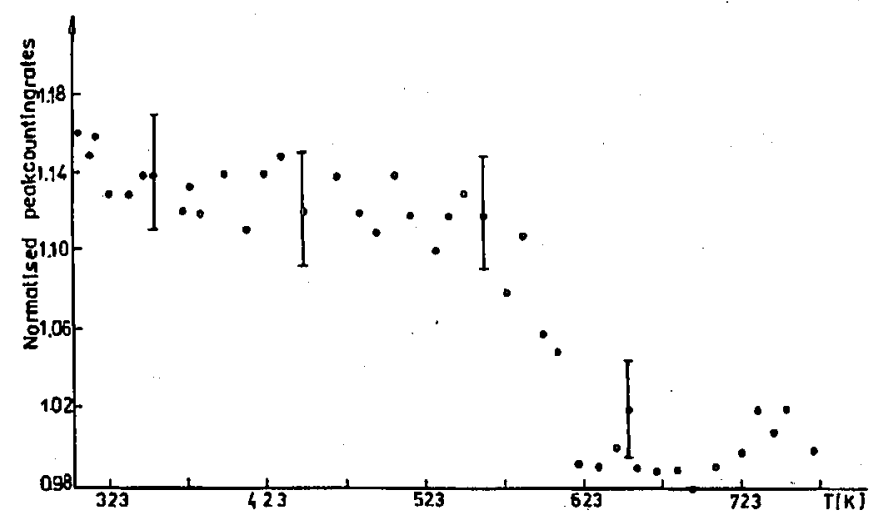

Fig. 4. The isochronal annealing curve for cold rolled helium free $\mathrm{Ni}$ sample.

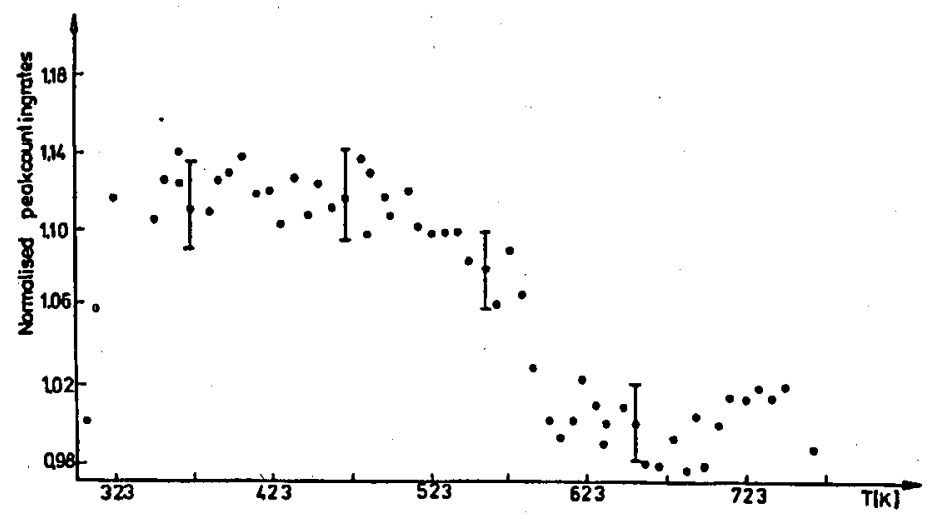

Fig. 5. The isochronal annealing curve for cold rolled and charged with helium $\mathrm{Ni}$ sample. 
As can be seen from Fig. 1, the cold rolled sample contains many lattice defects. The peak counting rate for the cold rolled sample is much higher (14\%) than the one for the well annealed sample. The process of cold rolling produces the vacancies, voids and dislocations. Charging with helium does not substantially change the shape of the correlation curve for the well annealed sample (Fig. 2). Small differences between the angular correlation curves (Fig. 2) result, most probably, from the presence of defects created by the ion bombardment during charging with helium. Introduction of helium substantially changes the shape of the angular correlation curve for the cold rolled sample (Fig. 3). The decrease in the peak counting rate $(10 \%)$ suggests that the defect concentration seen by the positron is decreased, resulting from the appearence of substitutional helium atoms. The data of the positron lifetime measurements [5] confirm this suggestion. From the isochronal annealing curve (Fig. 5 ) it is seen that the peak counting rate, for cold rolled and helium charged $\mathrm{Ni}$ samples, increases from the room temperature up to $350 \mathrm{~K}$. It can indicate that helium is released from defects in this range of temperature.

The He-defect binding energy estimated on the basis of our data is about $0.03 \mathrm{eV}$. This value is much different from the calculated He-vacancy binding energy that is $2.6 \mathrm{eV}$ [6]. Our value is closer to the theoretically estimated He-dislocation binding energy $0.3 \mathrm{eV}$ [7].

\section{Conclusions}

As follows from the results presented above, introduction of helium into cold rolled $\mathrm{Ni}$ samples causes remarkable changes in the correlation curves as well as in the isochronal annealing curves. The changes suggest that helium is trapped at crystal lattice defects. We can believe that, instead of voids, these defects are dislocations. The estimated He-dislocation binding energy is $0.03 \mathrm{eV}$.

\section{References}

[1] B. Viswanathan, G. Kogel, D. Sperr, W. Trifthauser, in: Positron Annihilation, Eds. P.G. Coleman, S.C. Sharma, L.M. Diana, North-Holland, Amsterdam 1982, p. 520.

[2] K.V. Jensen, B.N. Singh, M. Eldrup, M. Victoria, W.V. Green, Positron Annihilation, Eds. P.C. Jain, R.M. Singru, K.P. Gopinathan, World Science, Singapore 1985, p. 473.

[3] H.E. Hansen, H. Rajaiamaki, R.M. Nieminen, S. Linderoth, K. Petersen, in Ref. [2], p. 512.

[4] Y. Iwase, A. Uedeno, S. Tanigawa, in Ref. [2], p. 868.

[5] J. Pająk, B. Rozenfeld, Phys. Status Solidi A 104, K85 (1987).

[6] C.L. Bisson, W.D. Wilson, Tritium Technology in Fission, Fusion and Isolopic Applications, American Nuclear Soc. National Topical Conf. Dayton, OH, 1980, p. 78.

[7] M.J. Baskes, C.F. Melius, W.D. Wilson, in: Interatomic Potentials and Crystalline Defects, Ed. J.K. Lee, TMS - AIME Warrendale, P.A. 1981, p. 249. 